\title{
GESTÃO DOS CUSTOS EM UMA PROPRIEDADE LEITEIRA FAMILIAR DO SUL DE MINAS GERAIS ${ }^{1}$
}

\author{
Leandro Carvalho Bassotto ${ }^{2}$ \\ Luiz Kennedy Cruz Machado
}

\section{RESUMO}

A gestão dos custos é fundamental para contribuir com o bom gerenciamento da atividade leiteira e pode contribuir para que melhores resultados econômicos para propriedades leiteiras familiares sejam alcançados. Este estudo teve por objetivo analisar os custos de produção de uma propriedade familiar produtora de leite e verificar a contribuição da pecuária leiteira para o desenvolvimento econômico para produtores familiares. Foi realizada uma pesquisa quantitativa e descritiva, configurada como estudo de caso em uma propriedade leiteira situada no sul do Estado de Minas Gerais para analisar questões relacionadas aos custos de produção e resultados econômicos da atividade com dados coletados entre os anos de 2010 e 2017. A produção de leite da propriedade esteve a maior parte dos anos abaixo do ponto de equilíbrio. As receitas da atividade não foram capazes de remunerar o custo operacional total (COT) e o custo total (CT) na maioria dos anos analisados. Contudo, os resultados sugerem que a gestão dos custos da propriedade analisada está se desenvolvendo, pois os resultados econômicos dos últimos anos foram melhores que aqueles obtidos nos primeiros anos da pesquisa. A pecuária leiteira se mostrou como uma importante fonte geradora de riqueza e renda para produtores de leite familiares.

Palavras-chave: Custos econômicos. Custos de produção. Custos operacionais.

\section{MANAGEMENT OF COSTS IN A FAMILY MILK PROPERTY OF SOUTH OF MINAS GERAIS}

\begin{abstract}
Cost management is fundamental to contribute to the good management of dairy farming and can contribute to achieving better economic results for family dairy farms. This study aimed to analyze the production costs of a family farm producing milk and to verify the contribution of dairy farming to the economic development for family farmers. A quantitative and descriptive research was carried out, configured as a case study in a dairy property located in the south of the State of Minas Gerais to analyze issues related to production costs and economic results of the activity with data collected between the years 2010 and 2017. A Most of the years' milk production has been below break-even point. The activity's revenues were not able to remunerate the total operational cost (COT) and the total cost (CT) in most of the
\end{abstract}

\footnotetext{
${ }^{1}$ Como citar este artigo: BASSOTTO, L. C.; MACHADO, L. K. C. Gestão dos custos em uma propriedade leiteira familiar do sul de Minas Gerais.ForScience, Formiga, v. 8, n. 2, e00528, jul./dez. 2020. DOI: 10.29069/forscience.2020v8n2.e528.
}

²Autor para correspondência: Leandro Carvalho Bassoto, e-mail: bassoto.lc@gmail.com 
years analyzed. However, the results suggest that the management of the costs of the analyzed property is developing, since the economic results of the last years were better than those obtained in the first years of the research. Dairy farming proved to be an important source of wealth and income for family milk producers.

Keywords: Economic costs. Production costs. Operational costs.

\section{INTRODUÇÃO}

A bovinocultura leiteira é uma importante fonte geradora de emprego e renda para a agricultura familiar brasileira. Existe grande heterogeneidade quanto aos sistemas de produção, gerenciamento e outras atividades ligadas à produção de leite, fato que deixa sua viabilidade econômica em condição de risco (ASSIS et al., 2017). Atuar na gestão de empreendimentos rurais contribui com seu crescimento, oferecendo subsídios que permitam enfrentar eventuais crises que venham a interferir nos resultados da empresa.

Conhecer aspectos relacionados aos custos da cadeia produtiva do leite é fundamental para contribuir com o desenvolvimento do setor uma vez que, conforme cita Porter (1989), tais práticas permitem a agregação de vantagem competitiva às empresas. A gestão dos custos é indispensável para a sobrevivência de empreendimentos, fato que denota a importância de se desenvolver melhores políticas de gerenciamento dos custos de produção dentro das unidades produtivas do leite.

Diante da importância da pecuária leiteira para o contexto agropecuário e para a geração de riqueza e renda para a agricultura familiar, essa pesquisa justifica-se pela necessidade de compreensão dos custos de produção para a cadeia produtiva do leite e sua importância para o setor do agronegócio. Do mesmo modo, a presente pesquisa visa analisar ao seguinte problema de pesquisa: (I) a gestão dos custos pode contribuir para a melhoria da renda de uma propriedade leiteira familiar do sul de Minas Gerais? (II) A pecuária leiteira tem se mostrado eficiente para o desenvolvimento econômico da propriedade familiar em estudo?

Este estudo teve por objetivo analisar os custos de produção de uma propriedade familiar produtora de leite e verificar a contribuição da pecuária leiteira para o desenvolvimento econômico para produtores familiares.

\section{FUNDAMENTAÇÃO TEÓRICA}


A produção de leite como atividade comercial tem se desenvolvido continuamente, sendo responsável pelo fortalecimento econômico de inúmeras propriedades familiares (CORRÊA et al., 2015). A produção de leite no Sul do Estado de Minas Gerais pode ser considerada um importante setor do agronegócio responsável pelo desenvolvimento de pequenas propriedades familiares (LIZOT et al., 2017).

Inúmeras são as dificuldades que assolam as propriedades leiteiras familiares. Muitas famílias encontram-se em condição de despreparo profissional para gerenciar economicamente a atividade leiteira (LOPES et al., 2016). A limitação proveniente do desenvolvimento gerencial compromete o desempenho produtivo da atividade leiteira e a geração de renda da agricultura familiar (SORJ, 2001). Não obstante, o desenvolvimento gerencial dos custos de sistemas de produção de leite é um desafio a ser superado (DOMINGUEZ et al., 2014).

A gestão dos custos contribui com o desenvolvimento de análises de riscos de negócios agropecuários (RAMOS et al., 2015). Análises econômicas contribuem com o desenvolvimento de melhores parâmetros gerenciais para o desenvolvimento do processo produtivo (ROSSLER; GIUSIANO; BLANGETTI, 2016). O resultado são sistemas produtivos mais eficientes com maior capacidade de retornos econômicos (SABBAG; COSTA, 2015).

Conhecer os custos de produção é fundamental para uma gestão satisfatória da pecuária leiteira (ASSIS et al., 2017). Por meio dos custos de produção, produtores rurais conseguem corrigir falhar produtivas e garantir melhores competitividades no mercado (LOPES; SANTOS; CARVALHO, 2011). Custos de produção podem ser entendidos como todos os gastos ligados ao processo de produção da atividade leiteira (ASSIS et al., 2017) sejam desembolsáveis (com dispêndio monetário, exemplo: alimentação) ou não desembolsáveis (sem dispêndio monetário, exemplo: depreciações) (AGUIAR; ALMEIDA, 2002). Diferentes metodologias podem ser utilizadas para analisar custos de produção da pecuária leiteira. Duas são destacadas: custos econômicos e custos operacionais de produção.

Os custos econômicos são aqueles que analisam todos os custos fixos e variáveis da atividade leiteira (GOMES, 1999). Conhecer esses custos é fundamental para que elevados padrões de gestão em longos períodos de tempo sejam assegurados (BRIZOLLA et al., 2017). Custos fixos são todos os gastos que ocorrem independentemente da escala de produção (ALONSO, 1999). Custos variáveis são todos os gastos que variam conforme a produção (ASSIS et al., 2017). 
Custos operacionais de produção consideram todos os dispêndios monetários, chamados de efetivos e o somatório dos dispêndios monetários e não monetários, denominados totais (MATSUNAGA; BEMELMANS; TOLEDO, 1976). São exemplos do custo operacional efetivo (COE) os gastos com alimentação, melhoramento genético, qualidade do leite, entre outros (LAVORATO; BRAGA, 2017). O custo operacional total (COT) é composto pelo COE, depreciações de máquinas, equipamentos e benfeitorias e pela remuneração do(s) proprietário(s) que trabalha(m) na atividade leiteira (MATSUNAGA; BEMELMANS; TOLEDO, 1976).

O conceito de custos operacionais também considera o custo total (CT). Compõem esse custo o COT e a remuneração do capital investido na atividade (MARTIN et al., 1998), sendo considerado um custo de oportunidade. Custo de oportunidade é o retorno recebido pelo capital aplicado em um investimento alternativo (ASSIS et al., 2017), normalmente considerando a caderneta de poupança (LOPES et al., 2003).

\section{MATERIAL E MÉTODOS}

A presente pesquisa é de natureza quantitativa com abordagem descritiva. Segundo Vieira (2002), esse tipo de pesquisa é utilizado para conferir maior familiaridade entre o pesquisador e o objeto de estudo, permitindo uma melhor explicitação dos dados analisados. Seu principal objetivo é compreender aquilo que se pretende estudar (MALHOTRA, 2001).

Os dados foram coletados diretamente na fonte a que essa pesquisa se dedicou estudar, classificados como dados primários (VIEIRA, 2002; GIBBS, 2009). Dados primários tendem a apresentar menores possibilidades de distorção que surgem de consecutivas manipulações dos dados, motivo pelo qual podem ser considerados como dados de maior confiabilidade (GIBBS, 2009).

A coleta dos dados foi realizada mensalmente por um profissional técnico de extensão rural que prestou consultorias para essa propriedade entre os anos de 2010 e 2017. O objetivo inicial dessas consultorias consistia no aprimoramento do desenvolvimento técnico e gerencial da referida propriedade, motivo pelo qual a gestão dos custos mostrou-se fundamental para o cotidiano da propriedade leiteira.

A propriedade agrícola responsável pela geração dos dados era composta por uma área de 16,5 hectares (ha) até o ano de 2014. A partir do ano de 2015 , com a aquisição de uma nova área destinada para a produção agropecuária, passou a totalizar 19 ha, além de 1 ha 
arrendado desde o ano de 2010 e utilizado para a produção pecuária. Nesse total, está incluso 1 ha alugado de terceiros para que a atividade produtiva pudesse ser desenvolvida.

São consideradas áreas produtivas todas as áreas necessárias para o processo de produção, conforme a numeração apresentada na Figura 1 (1, 2 e 7) plantio de milho para silagem e/ou colheita de grãos; (3) benfeitorias; (4) criação de animais em crescimento com menos de uma ano de vida; (5) área de descanso dos animais; (6) pastagem rotacionada; e (7) área destinada para o crescimento de animais com mais de um ano de vida.

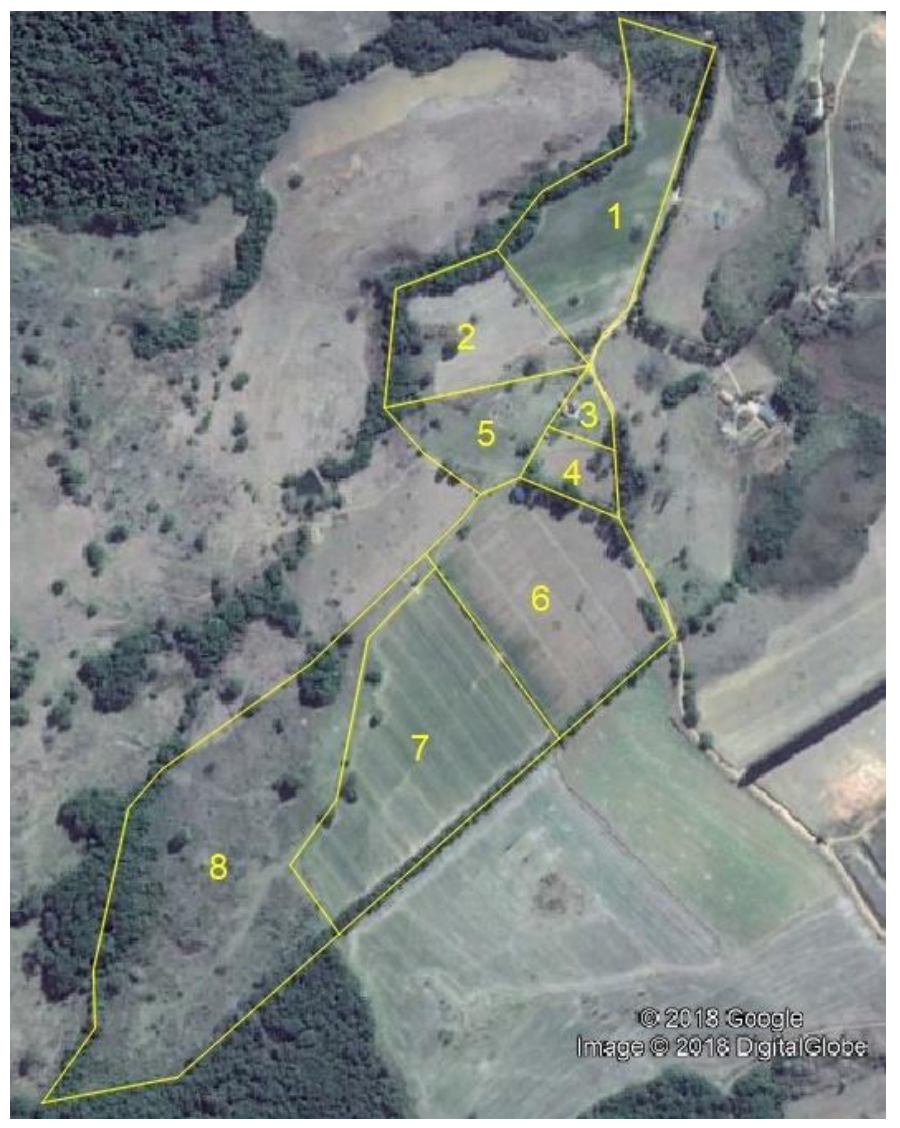

Figura 1 - Divisão das áreas de uma propriedade leiteira familiar, localizada no Sul do Estado de Minas Gerais em 2018 Fonte: Adaptado de Google Earth Pro (2018).

A propriedade é classificada como familiar, seguindo os conceitos de Nahum e Santos (2018) que advertem que não podem haver contratações permanentes na agricultura familiar, sendo possível apenas contratações temporárias para prestar algum suporte à família. Somente os cônjuges, proprietários, realizam as atividades necessárias para o funcionamento do processo produtivo do leite nessa propriedade.

\section{1 Procedimentos de análise dos dados}


Os dados foram coletados por um técnico da área de assistência técnica e extensão rural que assistiu a propriedade entre os anos de 2010 e 2017. Os dados foram inseridos em uma planilha do software Excel ${ }^{\circledR}$. Com base nesses dados, foram calculados os principais indicadores econômicos a serem apresentados na presente pesquisa. Os dados foram classificados em investimentos, custos fixos e variáveis e os custos operacionais efetivo (COE) e total (COT).

São componentes do investimento todo capital investido em animais, máquinas, equipamentos, terra e benfeitorias, englobando todos os desembolsos que aumentam o patrimônio da empresa (LOPES et al., 2018). Os custos variáveis são compostos pelos gastos com mão de obra temporária, alimentação, melhoramento genético, qualidade do leite, sanidade e outros gastos que variam conforme a produção. Os custos fixos englobam as depreciações, taxas e impostos, manutenção de benfeitorias, arrendamentos, pagamento de juros, assistência técnica e outros gastos que ocorrem independentemente da produção.

O COE é composto pelos custos fixos e variáveis desembolsáveis (MATSUNAGA; BEMELMANS; TOLEDO, 1976). O COT é formado pelo somatório do COE com as depreciações das benfeitorias, máquinas e equipamentos e a remuneração do (s) proprietário (s) (PEREIRA et al., 2017). O CT formado pela soma do COT com a remuneração do capital total investido da atividade leiteira (LAVORATO; BRAGA, 2017).

Com esses dados, foram calculados os seguintes indicadores: ponto de equilíbrio, quando se divide o somatório dos custos fixos e depreciações pela margem de contribuição unitária (LOPES; SANTOS; CARVALHO, 2011). A receita bruta (RB) é resultado da soma da venda de leite, animais e outras fontes geradoras de capital monetário provenientes da pecuária leiteira (PEREIRA et al., 2017). A margem bruta (MB) é calculada no RB descontado o COE (MACIEL et al., 2018). - A margem líquida é calculada da RB descontado o COT (LAVORATO; BRAGA, 2017). O lucro econômico (L) é resultado da RB descontado o CT (MATSUNAGA; BEMELMANS; TOLEDO, 1976). A metodologia de cálculo dos índices acima citados foi realizada com todos os dados anuais da propriedade nos anos de suas respectivas coletas.

\section{RESULTADOS E DISCUSSÃO}


Os custos fixos e variáveis apresentaram características distintas (Tabela 1). As depreciações representaram o maior valor dos custos fixos ocorridos nos anos de 2010 a 2013. Nos anos posteriores, outros custos apresentaram valores superiores: juros pagos a terceiros (2014 e 2016), taxas e impostos (2015). Nos custos variáveis, o principal componente é a alimentação, que correspondeu a $88 \%$ e $80 \%$ do total dos custos variáveis nos anos de 2010 e 2017, respectivamente. Esses valores foram muito superiores àqueles obtidos por outros autores que realizaram estudos semelhantes: 68\% (ASSIS et al., 2017) e 57\% (LAZARINI; LOPES; CARDOSO, 2017).

Tabela 1 - Composição dos custos fixos e variáveis de uma propriedade leiteira familiar localizada no Sul do Estado de Minas Gerais entre os anos de 2010 e 2017

\begin{tabular}{cccccccccc}
\hline \multicolumn{10}{c}{ CUSTOS VARIÁVEIS } \\
\hline Item & $\mathbf{2 0 1 0}$ & $\mathbf{2 0 1 1}$ & $\mathbf{2 0 1 2}$ & $\mathbf{2 0 1 3}$ & $\mathbf{2 0 1 4}$ & $\mathbf{2 0 1 5}$ & $\mathbf{2 0 1 6}$ & $\mathbf{2 0 1 7}$ & $\begin{array}{c}\text { Desvio } \\
\text { Padrão }\end{array}$ \\
\hline 1 & 580,00 & $2.508,00$ & $4.019,00$ & $2.773,00$ & $3.787,50$ & $1.130,00$ & 580,00 & $2.265,00$ & $1.257,47$ \\
2 & $22.955,00$ & $24.282,75$ & $27.924,70$ & $31.934,46$ & $52.735,17$ & $41.376,80$ & $22.955,00$ & $51.350,07$ & $11.643,08$ \\
3 & 0,00 & 12,00 & 380,00 & 80,00 & 400,00 & 480,00 & 0,00 & 390,80 & 198,24 \\
4 & $1.893,90$ & $3.378,50$ & $3.728,10$ & $8.012,30$ & $5.165,36$ & $5.718,30$ & $1.893,90$ & $8.579,90$ & $2.388,61$ \\
5 & 128,80 & 165,90 & 58,00 & 206,40 & 164,30 & 833,86 & 128,80 & $1.114,14$ & 369,15 \\
6 & 415,10 & 900,00 & 176,50 & 526,50 & 582,10 & $14.038,25$ & 415,10 & 675,34 & $4.472,71$ \\
\hline Total & $25.972,80$ & $31.247,15$ & $36.286,30$ & $43.532,66$ & $62.834,43$ & $63.577,21$ & $25.972,80$ & $64.375,25$ & $15.910,15$ \\
\hline \multicolumn{7}{c}{} & & \multicolumn{7}{c}{ CUSTOS FIXOS } & & & & \\
\hline 7 & $2.795,25$ & $2.630,82$ & $2.447,72$ & $2.308,77$ & $1.615,79$ & $1.524,48$ & $2.795,25$ & $1.985,93$ & 471,59 \\
8 & 0,00 & 0,00 & 0,00 & 0,00 & 0,00 & $3.343,58$ & 0,00 & $4.299,82$ & $1.672,02$ \\
9 & 44,50 & 561,80 & 801,60 & 961,00 & $2.178,55$ & 852,60 & 44,50 & $1.532,50$ & 672,90 \\
10 & 333,00 & 0,00 & 0,00 & 250,00 & 500,00 & $3.250,00$ & 333,00 & 600,00 & 999,40 \\
11 & 0,00 & 0,00 & 0,00 & 0,00 & $2.630,00$ & $1.078,00$ & 0,00 & $2.334,00$ & $1.058,50$ \\
12 & $1.000,00$ & 825,00 & 840,00 & 875,00 & 910,00 & $1.752,50$ & $1.000,00$ & $2.211,00$ & 482,57 \\
13 & 664,67 & 695,83 & 593,32 & 639,87 & 658,30 & $1.068,85$ & 664,67 & $1.257,35$ & 227,56 \\
\hline Total & $4.837,42$ & $4.713,45$ & $4.682,64$ & $5.034,64$ & $8.492,64$ & $12.870,01$ & $4.837,42$ & $14.220,60$ & $3.723,84$ \\
\hline CT & $30.810,22$ & $35.960,6$ & $40.968,94$ & $48.567,3$ & $71.327,07$ & $76.447,22$ & $30.810,22$ & $78.595,85$ & $19.633,99$ \\
\hline
\end{tabular}

Notas: ${ }^{1}$ Mão de obra temporária; ${ }^{2}$ Alimentação; ${ }^{3}$ Genética; ${ }^{4}$ Sanidade; ${ }^{5}$ Qualidade do leite; ${ }^{6}$ Outros custos variáveis. ${ }^{7}$ Depreciações; ${ }^{8}$ Taxas e impostos; ${ }^{9}$ Manutenção de benfeitorias; ${ }^{10}$ Arrendamento; ${ }^{11}$ Juros pagos; ${ }^{12}$ Assistência técnica; ${ }^{13}$ Outros custos fixos; ${ }^{*}$ Custo total

Fonte: dados da pesquisa.

À medida que a renda da propriedade aumenta (Figura 2), o impacto da utilização de alimentação equilibrada tende a diminuir denotando, segundo Lazarini, Lopes e Cardoso (2017), a importância da escala da produção para a minimização dos impactos dos custos variáveis. Tais resultados implicam dizer que o impacto desses custos ao longo do tempo tende a se manter equilibrado em unidades produtivas que detém eficiência de gestão e manejo das atividades de produção. 


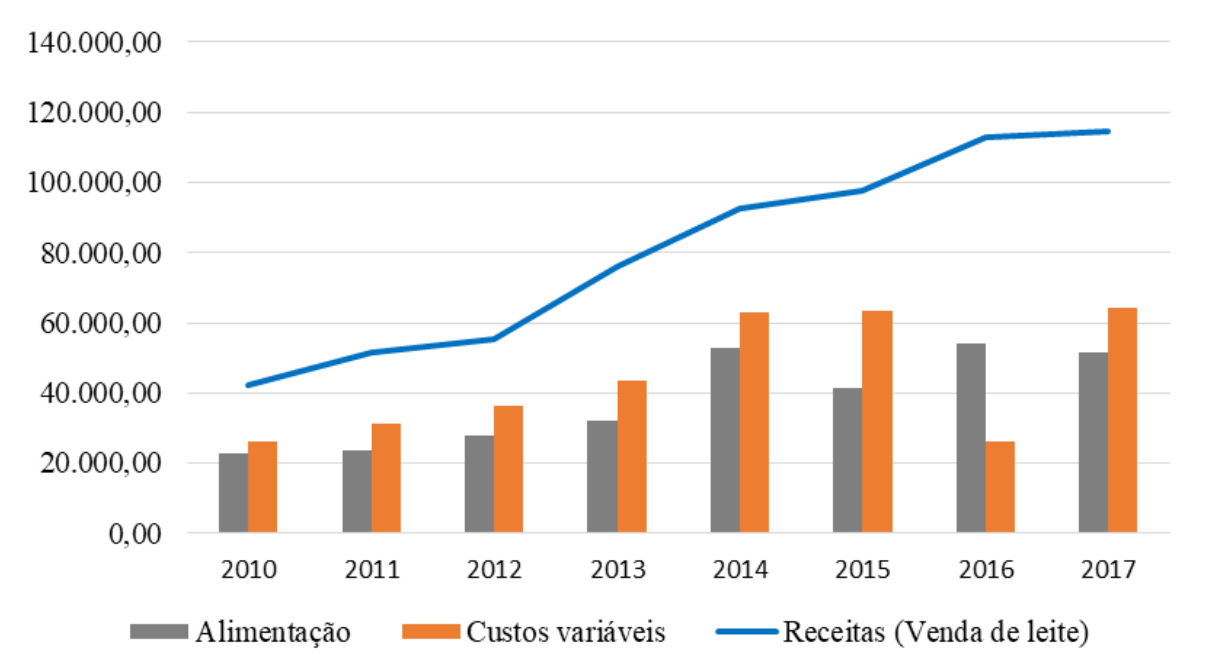

Figura 2 - Receitas obtidas com a venda de leite e os custos com alimentação e variáveis de uma propriedade leiteira familiar ocorridos entre os anos de 2010 a 2017 Fonte: dados da pesquisa.

Os custos fixos permitiram calcular o ponto de equilíbrio da propriedade analisada (Figura 3). Apenas em 2013 a produção média de leite por dia conseguiu superar os referidos custos. Um dos motivos foi a existência de depreciações que limitaram o desempenho econômico da propriedade. Assis et al. (2017) sugeriram que os custos de produção sejam trabalhados e que investimentos sejam realizados em momentos oportunos para que os custos fixos não se elevem em demasia.

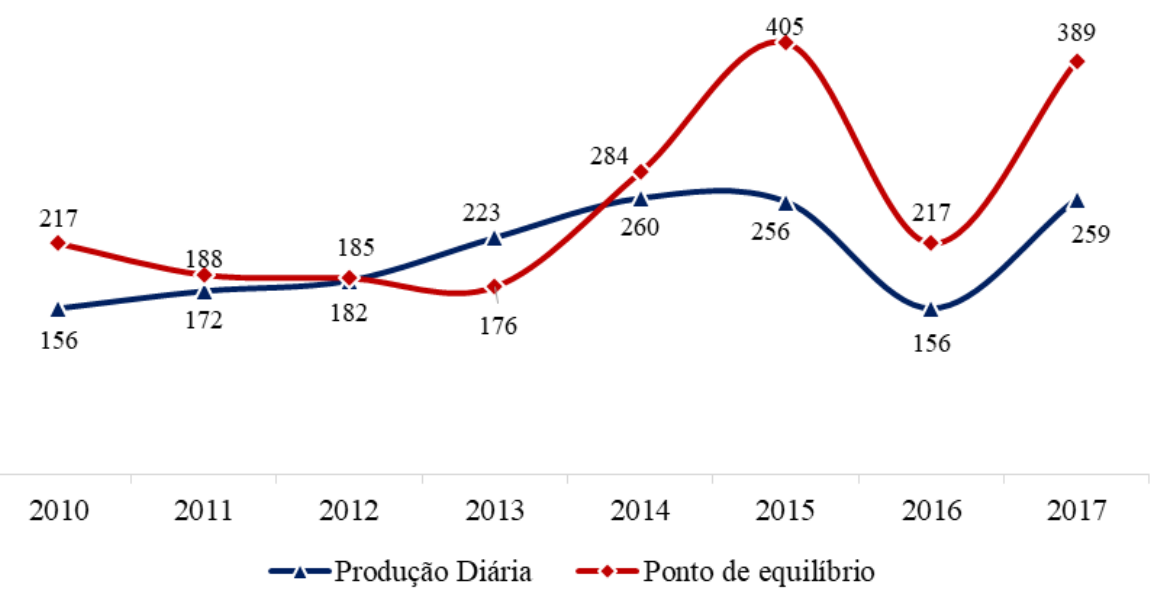

Figura 3 - Ponto de equilíbrio e produção (litros/dia) de uma propriedade leiteira localizada no Sul do Estado de Minas Gerais entre os anos de 2010 e 2017

Fonte: Dados da pesquisa.

Quando analisados os custos operacionais da atividade, constatou-se que o CT elevouse em aproximadamente $152 \%$ entre o primeiro e o último ano (Tabela 2). O COE aumentou 
$173 \%$ e o COT elevou-se em torno de $150 \%$. Esses resultados discordam de Ribeiro, Silva e Leite (2018), ao argumentarem que esses custos são diluídos com o aumento da produção leiteira.

A remuneração dos proprietários foi calculada seguindo os preços praticados pelo mercado no decorrer dos anos. Seu aumento girou em torno de $140 \%$ entre o primeiro e o último ano analisados. Estão inclusos na remuneração do capital investido os valores patrimoniais dos animais e da terra, ambos utilizados para a produção de leite. Foi considerado como custo de oportunidade a taxa Selic média dos anos de 2010 a 2017 cujo valor foi de 9,9\% ao ano (PORTAL DO BRASIL, 2018).

Tabela 2- Custos operacionais e total de uma propriedade de leite situada em Caldas/MG

\begin{tabular}{cccccccccc}
\hline Item & $\mathbf{2 0 1 0}$ & $\mathbf{2 0 1 1}$ & $\mathbf{2 0 1 2}$ & $\mathbf{2 0 1 3}$ & $\mathbf{2 0 1 4}$ & $\mathbf{2 0 1 5}$ & $\mathbf{2 0 1 6}$ & $\mathbf{2 0 1 7}$ & $\begin{array}{c}\text { Desvio } \\
\text { Padrão }\end{array}$ \\
\hline CT $^{\mathbf{1}}$ & $65.091,66$ & $74.877,80$ & $83.023,37$ & $94.593,73$ & $125.301,81$ & $138.531,92$ & $161.641,92$ & $164.676,93$ & $36.782,99$ \\
$\mathrm{RCI}^{2}$ & $22.281,44$ & $25.717,20$ & $27.654,42$ & $30.426,42$ & $35.974,73$ & $41.684,70$ & $44.526,00$ & $57.281,07$ & $10.907,50$ \\
COT $^{\mathbf{3}}$ & $\mathbf{4 2 . 8 1 0 , 2 2}$ & $\mathbf{4 9 . 1 6 0 , 5 9}$ & $\mathbf{5 5 . 3 6 8 , 9 4}$ & $\mathbf{6 4 . 1 6 7 , 3 1}$ & $\mathbf{8 9 . 3 2 7 , 0 7}$ & $\mathbf{9 6 . 8 4 7 , 2 2}$ & $\mathbf{1 1 7 . 1 1 5 , 9 1}$ & $\mathbf{1 0 7 . 3 9 5 , 8 6}$ & $\mathbf{2 6 . 5 7 7 , 3 0}$ \\
$\mathrm{RP}^{4}$ & $12.000,00$ & $13.200,00$ & $14.400,00$ & $15.600,00$ & $18.000,00$ & $20.400,00$ & $24.000,00$ & $28.800,00$ & $5.424,94$ \\
$\mathrm{DM}^{5}$ & $2.386,51$ & $2.246,54$ & $2.086,40$ & $1.968,99$ & $1.315,10$ & $1.241,50$ & $1.279,97$ & $1.734,98$ & 429,13 \\
$\mathrm{DI}^{6}$ & 408,74 & 384,27 & 361,32 & 339,79 & 300,69 & 282,98 & 266,42 & 250,96 & 54,002877 \\
$\mathrm{COE}^{\mathbf{7}}$ & $\mathbf{2 8 . 0 1 4 , 9 7}$ & $\mathbf{3 3 . 3 2 9 , 7 8}$ & $\mathbf{3 8 . 5 2 1 , 2 2}$ & $\mathbf{4 6 . 2 5 8 , 5 3}$ & $\mathbf{6 9 . 7 1 1 , 2 8}$ & $\mathbf{7 4 . 9 2 2 , 7 4}$ & $\mathbf{9 1 . 5 6 9 , 5 2}$ & $\mathbf{7 6 . 6 0 9 , 9 2}$ & $\mathbf{2 2 . 1 3 1 , 9 3}$ \\
\hline
\end{tabular}

Notas: ${ }^{1}$ Custo total; ${ }^{2}$ remuneração de capital investido; ${ }^{3}$ custo operacional total; ${ }^{4}$ remuneração dos proprietários; ${ }^{5}$ depreciação de máquinas; ${ }^{6}$ depreciação de instalações; custo operacional efetivo.

Fonte: Dados da pesquisa.

O aumento dos preços da remuneração do capital investido ocorreu devido à elevação do patrimônio da atividade leiteira que passou de $\mathrm{R} \$ 225.065,00$ em 2010 para $\mathrm{R} \$ 578.596,70$ em 2017, elevação aproximada de 157\%. A atividade contribuiu com o desenvolvimento do patrimônio da família, uma vez que a taxa de crescimento ficou em torno de 19,6\% ao ano. A esse respeito, Dias (2018) salientou que quanto mais elevada for a taxa de crescimento patrimonial, maior tenderá a ser a atratividade desse negócio agropecuário no mercado.

A variação dos custos operacionais e total influiu no desempenho da atividade que não conseguiu remunerar os três custos (Figura 4). As receitas apresentaram melhora no decorrer dos anos, pois a margem líquida (ML) apresentou tendência ascendente. A ML é fundamental para o desempenho econômico de propriedades leiteiras familiares, Assis et al. (2017) corroboram com esse entendimento e acrescentam que esse é um indicador que permite analisar as receitas e os custos que, isoladamente, não contribuiriam significativamente com o conhecimento da condição econômica real de uma propriedade familiar. 
Em 2015 a propriedade adquiriu uma área de 2,4 ha, realizando o pagamento no ano da compra e no ano posterior. Por esse motivo, houve maior venda de animais em 2016, fato que justifica a elevação da ML. Foi possível constatar a venda de animais também nos anos de 2014 e 2017, porém em maior quantidade, explicando a elevação da ML nesses anos. Pode-se inferir que a venda de animais é fundamental para que melhores resultados sejam auferidos na atividade leiteira. Esse estudo corrobora com os resultados obtidos por Moura et al. (2010) e Corrêa et al. (2017) que apresentaram o mesmo entendimento sobre esse tipo de receita.

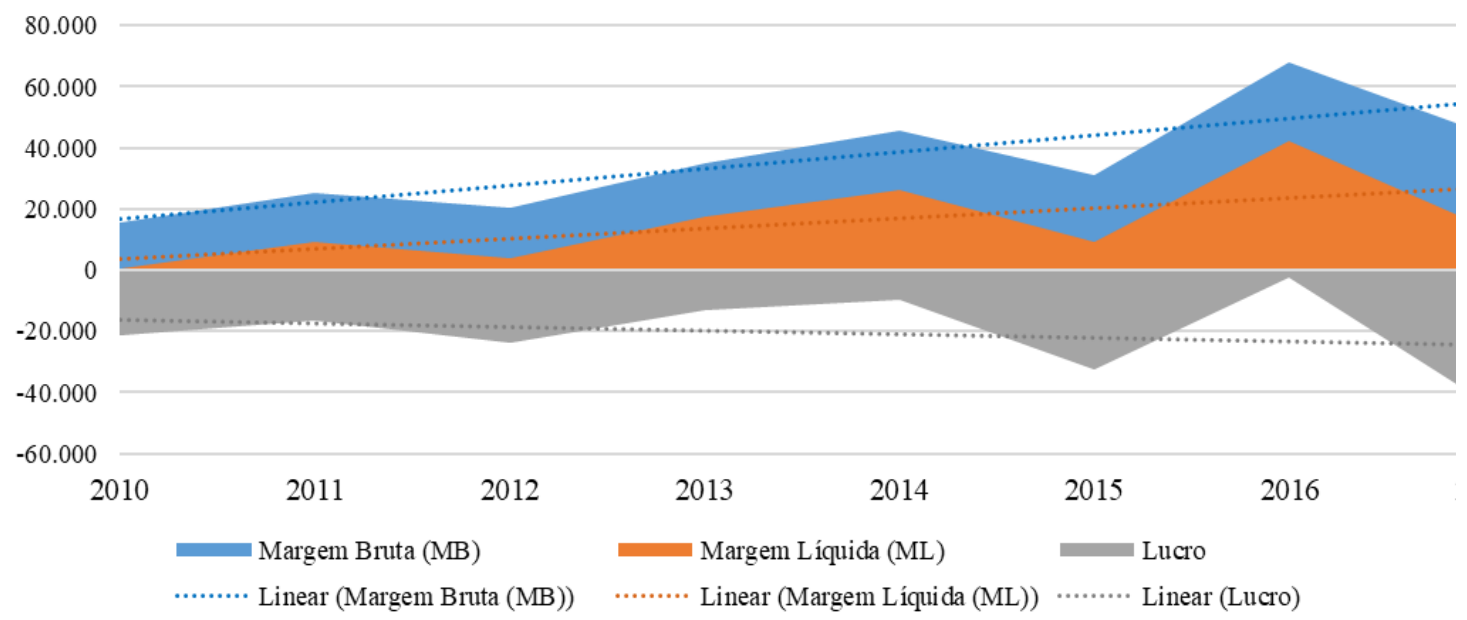

Figura 4 - Margem bruta, margem líquida e lucro (em reais) de uma propriedade leiteira familiar localizada no município de Caldas, Sul do Estado de Minas Gerais, entre os anos de 2010 e 2017

Fonte: Dados da pesquisa.

A propriedade não conseguiu obter lucro (L) com a atividade leiteira. Por se tratar de um indicador de oportunidade, entende-se que a atividade econômica do leite ainda não foi capaz de superar o custo de oportunidade do investimento do capital monetário empatado com o processo produtivo.

Quando se considerou a variação do custo operacional efetivo em detrimento dos investimentos da propriedade (Figura 5), foi possível identificar o baixo volume de capital investido. Houve investimento considerável apenas em 2015, ano em que foi realizada a compra de um hectare de terra. Embora tenha havido um aporte de investimento superior aos montantes normais da série histórica, o aumento anual dos investimentos sofreu modesta elevação desde o primeiro ano analisado.

As receitas totais indicaram ascensão com maior participação no decorrer dos anos, permitindo compreender que os investimentos ocorridos nessa propriedade corroboraram com o aumento das receitas totais, uma vez que as receitas subiram em níveis superiores aos 
identificados nos investimentos. As despesas de custeio mantiveram-se em uma crescente equilibrada, permanecendo dentro dos limites aceitáveis.

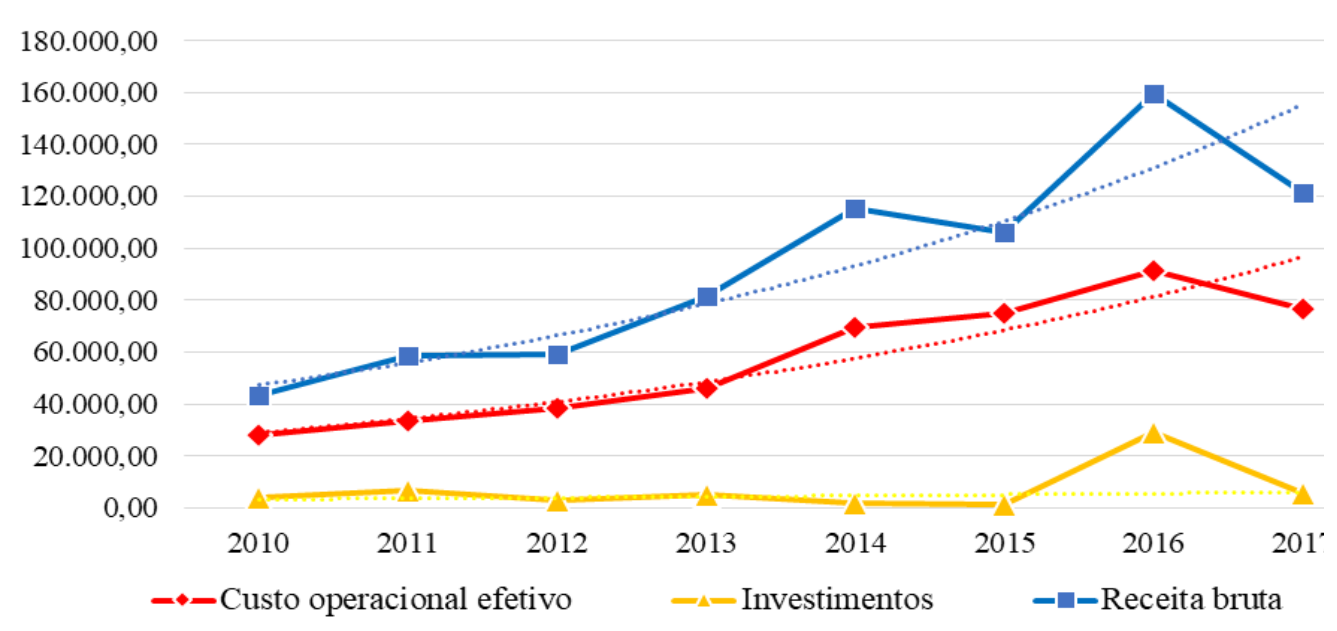

Figura 5 - Custo operacional efetivo, investimento e receita bruta de uma propriedade leiteira familiar localizada no Sul do Estado de Minas Gerais entre os anos de 2010 a 2017

Fonte: Dados da pesquisa.

As análises sobre os custos operacionais por litro de leite produzido indicaram resultados diferentes quando se excluíram das receitas a venda de animais (Figura 6). As receitas com a venda do leite pagaram apenas o $\mathrm{COE}$, conferindo $\mathrm{MB}$ positiva. $\mathrm{O}$ cenário que incorreu resultados melhores sobre preço de venda do leite e o COT foi em 2017 quando os valores se equipararam. Contudo, a variação entre o COT e a média geral de preços foi se aproximando no decorrer dos anos analisados. Depreende-se que houve uma valorização no preço de venda do leite aliada a uma gestão eficiente dos custos que contribuiu para que o COT não apresentasse elevação significativa.

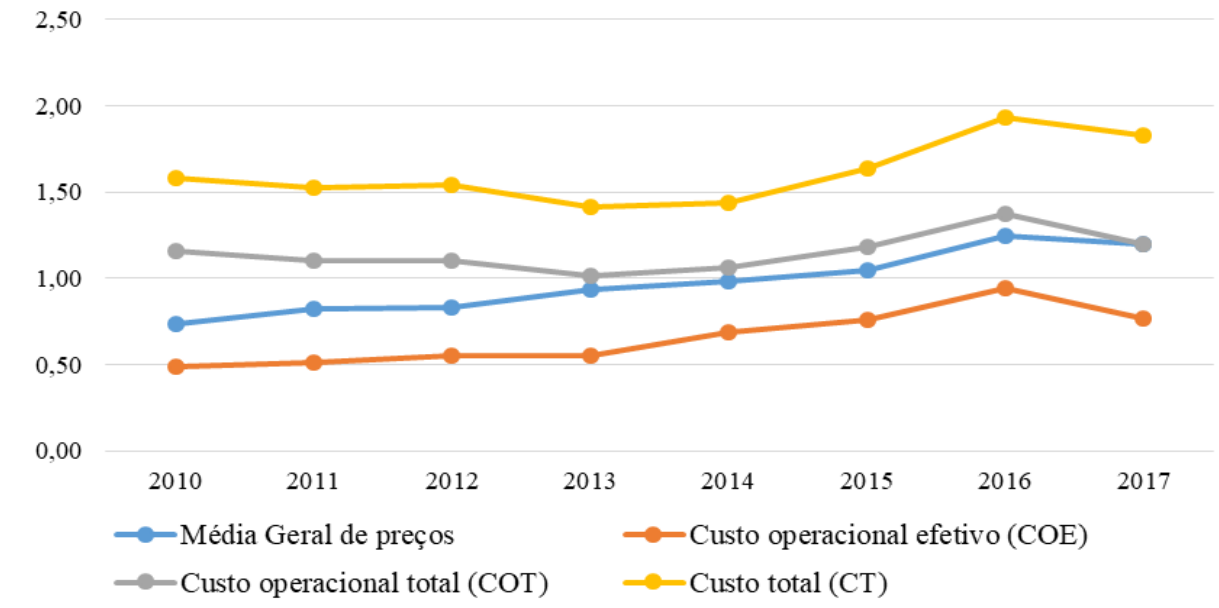

Figura 6 - Variação dos custos operacionais e total (R $\$ /$ litro) e dos preços de venda do leite (R\$) em uma propriedade leiteira localizada no Sul do Estado de Minas Gerais entre os anos de 2010 a 2017

Fonte: Dados da pesquisa. 
Ao se analisar a variação do preço de venda do leite na série histórica, constatou-se que os anos de 2013, 2016 e 2017 apresentaram maior variação entre o preço mínimo e o preço máximo pago pelo litro de leite (Figura 7). O preço médio de venda nos anos de 2013 e 2016 esteve mais próximo do valor máximo, indicativo que os preços de venda se mantiveram elevados na maior parte do ano. A mesma conclusão pode ser feita ao se observar os anos de 2010 e 2012 que se diferem dos primeiros apenas pela variação dos preços que foi menor. Preço de venda do leite mais estáveis contribuem com o planejamento da atividade leiteira que pode ser melhor desenvolvido (LHERMIE; TAUER; GRÖHN, 2018).

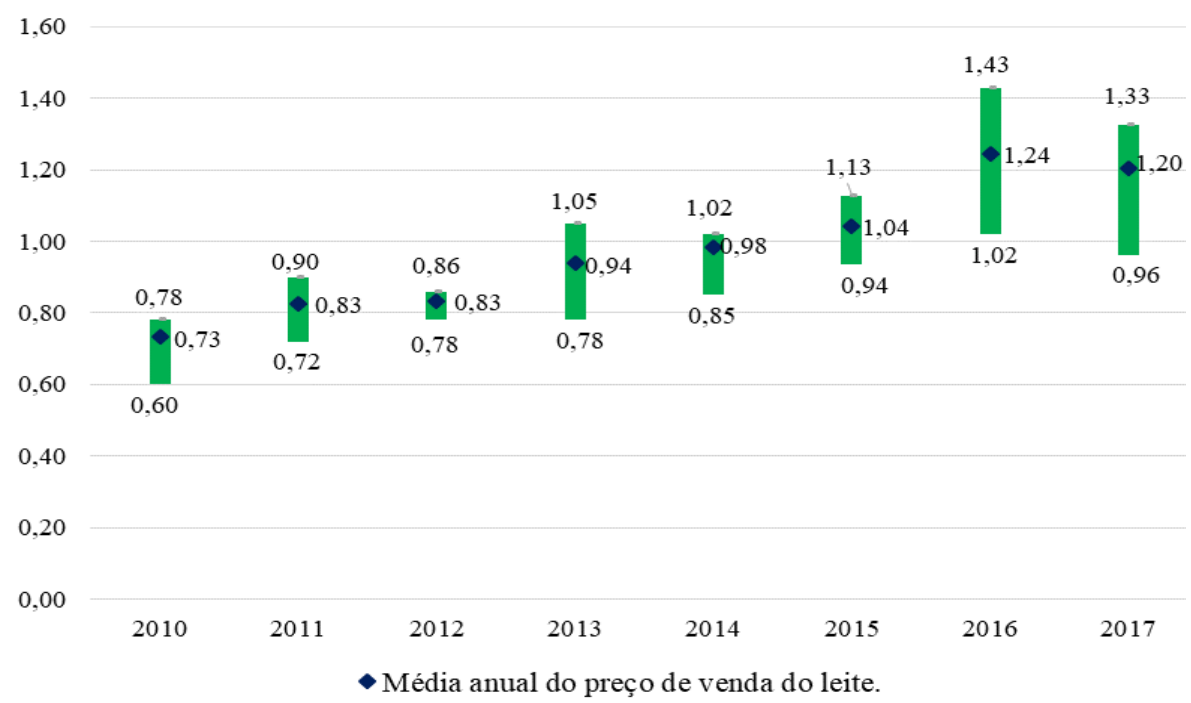

Figura 7 - Variação do preço de venda mínimo, máximo e médio ocorridos entre os anos de 2010 e 2017 em uma propriedade leiteira familiar localizada no Sul do Estado de Minas Gerais

Fonte: Dados da pesquisa.

A análise dos dados sugere que novas práticas zootécnicas são necessárias para que o processo produtivo da propriedade possa se desenvolver com rentáveis resultados econômicos. Pode-se inferir que a gestão dos custos da propriedade em questão tem se desenvolvido, pois os resultados econômicos apresentaram melhorias nos últimos anos.

\section{CONSIDERAÇÕES FINAIS}

Esse estudo teve por objetivo analisar os custos de produção de uma propriedade leiteira familiar com diferentes metodologias e verificar as contribuições da pecuária leiteira para o desenvolvimento de produtores familiares. Analisar os custos de produção da atividade leiteira foi fundamental para compreender comportamentos que não seriam identificados caso 
apenas uma metodologia fosse utilizada. Os investimentos contribuíram com o desempenho econômico da atividade leiteira.

A gestão dos custos demonstrou ser de fundamental importância, por permitir analisar o desenvolvimento da atividade, contribuindo com melhores tomadas de decisão para a melhoria dos resultados econômicos em propriedades familiares. Assim, a atividade leiteira se mostrou economicamente eficiente para o desenvolvimento de uma propriedade leiteira sul mineira. Contudo, ao considerar a taxa Selic como um índice de oportunidade, o lucro econômico da atividade foi negativo, indicativo de pouca atratividade da bovinocultura leiteira. O ponto de equilíbrio também se mostrou desfavorável em todos os anos, com exceção apenas em 2013.

A propriedade leiteira familiar apresentou alguns índices pouco satisfatórios, contudo foi possível identificar que o desenvolvimento econômico da atividade leiteira é contínuo, pois os resultados melhoraram no decorrer dos anos. A pecuária leiteira se mostrou um importante ramo de atividade para contribuir com o desenvolvimento de produtores familiares que retiram do campo a remuneração ideal para a continuidade das atividades agropecuárias com qualidade de vida.

Esse estudo foi fundamental para analisar a realidade de uma propriedade leiteira familiar. Contudo, sua aplicação é limitada ao contexto real do Sul do Estado de Minas Gerais devido à grande amplitude geográfica sul mineira. Sugere-se que novos estudos sejam realizados para que seja possível um diagnóstico mais detalhado do perfil de desenvolvimento econômico de propriedades leiteiras familiares da microrregião do Sul de Minas Gerais.

\section{REFERÊNCIAS}

AGUIAR, A. P. A.; ALMEIDA, B. H. P. J. F. Planejamento e administração da produção de leite e carne no Brasil. Uberaba: FAZU, 2002. 92 p.

ALONSO, M. Custos no serviço público. Revista do Serviço Público, Brasília, v. 50, n. 1, p. 37-63, jan./mar. 1999.

ASSIS, L. P. de et al. Análise econômica e de custos de produção da atividade leiteira durante 10 anos em uma propriedade do Alto Vale do Jequitinhonha. Custos e Agronegócio Online, Recife, v. 13, n. 2, p. 176-200, abr./jun. 2017.

BRIZOLLA, M. M. B. et al. Sistema de informação sob o enfoque do custeio variável em organizações agrícolas. Custos e Agronegócio Online, Recife, v. 13, n. 4, p. 257-282, out./dez. 2017. 
CORRÊA, R. G. de F. et al. Proposta de implantação de um sistema de custeio para bovinocultura de corte. Custos e Agronegócio Online, Recife, v. 11, n. 3, p. 227-256, jul./set. 2015.

CORRÊA, U. et al. Análise operacional da atividade leiteira do Instituto Federal de Educação, Ciência e Tecnologia de Minas Gerais - Campus Bambuí. Custos e Agronegócio Online, Recife, v. 13, p. 262-283, Edição Especial, abr. 2017.

DIAS, G. L. da. Avaliação do serviço de extensão rural: considerações gerais sobre o impacto econômico da extensão rural. Estudos Econômicos, São Paulo, v. 4, n. 3, p. 7-52, 2018.

DOMINGUEZ, R. R. P. et al. Análisis de costos y estratégias productivas em lalechería de pequeña escala em el periodo 2000-2012. Contaduría y Administración, México, v. 59, n. 2, p. 253-275, jun. 2014.

GIBBS, G. Análise de dados qualitativos: coleção pesquisa qualitativa. Porto Alegre: Bookman, 2009.

GOMES, S. T. Cuidados no cálculo do custo de produção de leite. In: SEMINÁRIO SOBRE METODOLOGIAS DE CÁLCULO DO CUSTO DE PRODUÇÃO DE LEITE, 1., 1999, Piracicaba. Anais [...]. Piracicaba: USP, 1999.

LAVORATO, M. P.; BRAGA, M. J. Custos de produção da soja no sistema convencional e no de precisão em Mato Grosso do Sul. Revista de Política Agrícola, Brasília, v. 26, n. 3, p. 22-30, 2017.

LAZARINI, G. P.; LOPES, M. A.; CARDOSO, M. G. Análise da disponibildiade de alimentos volumosos em propriedades leiteiras da agricultura familiar no município de Ponte Nova/MG: um estudo multicasos. Revista Acadêmica Ciência Animal, v. 15, n. 1, p. 49-57, 2017.

LHERMIE, G.; TAUER, L. W.; GRÖHN, Y. T. The farmcost of decreasing antimicrobial use in dairy production. PloSone, v. 13, n. 3, p. e0194832, 2018.

LIZOT, M. et al. Análise econômica da produção de aveia preta para pastejo e ensilagem utilizando a metodologia multi-índice ampliada. Custos e Agronegócio Online, Recife, v. 13, n. 2, p. 141-155, abr./jun.2017.

LOPES, M. A. et al. Rentabilidade de um sistema de produção de leite tipo B: um estudo de caso com a raça Jersey, no Estado de São Paulo. Revista Economia Rural, v. 2, n. 2, p. 215 221, 2003.

LOPES, M. A. et al. Análisis de la rentabilidad de la actividad lechera de propriedades participantes del programa "Balde Cheio". Revista de Medicina Veterinária, v. 38, n.1, p. 15-27, enero/junio, 2019.

LOPES. M. A.; SANTOS, G. dos; CARVALHO, F. de M. Estudo da rentabilidade de sistemas de produção de leite no município de Nazareno - Minas Gerais. Ciência Animal Brasileira, Goiânia, v. 12, n. 1, p. 58-69, 2011. 
LOPES, M. A. et al. Uso de ferramentas de gestão na atividade leiteira: um estudo de caso no sul de Minas Gerais. Revista Cientifica de Produção Animal, Areia, v. 18, n. 1, p. 26-44, 2016.

MACIEL, R. C. G. et al. Produção familiar rural e desigualdade de renda na Amazônia: um estudo do projeto reca, em Porto Velho, Rondônia. Revista de Estudos Sociais, Cuiabá, v. 20, n. 39, p. 3-18, 2018.

MALHOTRA, N. K. Pesquisa de marketing: uma orientação aplicada. 3 ed. Porto Alegre: Bookman, 2001.

MARTIN, N. B. et al. Sistema integrado de custos agropecuários CUSTAGRI. Informações Econômicas - Governo do Estado de São Paulo Instituto de Economia Agrícola, v. 28, p. 7 28, 1998.

MATSUNAGA, M.; BEMELMANS, P. F.; TOLEDO, P. E. N. de. Metodologia de custo de produção utilizada pelo IEA [Brasil]. Agricultura em São Paulo, São Paulo, v. 23, n. 1, p. 123-139, 1976.

MOURA, J. F. P. et al. Análise econômica da exploração de leite no cariri paraibano. Acta Scientiarum Animal Sciences, Maringá, v. 32, n. 2, p. 225-231, 2010.

NAHUM, J. S.; SANTOS, C. B. dos. Agricultura familiar e dendeicultura no município de Moju, na Amazônia paraense. Cuadernos de Geografía: Revista Colombiana de Geografía, Bogotá, v. 27, n. 1, 2018.

PEREIRA, L. C. et al. Desempenho e viabilidade econômica de bovinos precoces submetidos a diferentes níveis de suplementos. PUBVET, Maringá, v. 11, n. 7, p. 646-743, 2017.

PORTAL DO BRASIL. Taxa Selic. 2018. Disponível em: https://www.portalbrasil.net/ 2018/indices/indices_selic.htm. Acesso em: 21 set. 2019.

PORTER, M. E. A cadeia de valores e a vantagem competitiva. Vantagem competitiva: criando e sustentando um desempenho superior. Rio de Janeiro: Campus, p. 31-53, 1989.

RAMOS, Y. et al. Evaluación de los riesgos económicos y los costos de lacalidad em aa actividad ganadera de la CCSF Victoria de Girón, Matanzas, Cuba. Pastos y Forrajes, Matanzas, v. 38, n. 1, p. 80-84, mar. 2015.

RIBEIRO, G. M. M.; SILVA, N. de M.; LEITE, M. A. A mensuração do custo de produção da cultura de ovinos na agricultura familiar. QUALIA: a ciência em movimento, Goiânia, v. 3, n. 1, p. 49-74, 2018.

ROSSLER, N; GIUSIANO, J; BLANGETTI, D. Evaluación del impacto sobre el margen bruto de un conjunto de estrategias de manejo em la actividad lechera. FAVE. Sección Ciências Agrárias, Santa Fe, v. 15, n. 2, dic. 2016.

SABBAG, O. J.; COSTA, S. M. A. L. Análise de custos da produção de leite: aplicação do método de Monte Carlo. Extensão Rural, Santa Maria, v. 22, n. 1, p. 125-145, 2015. 
SORJ, B. Estado e classes sociais na agricultura brasileira. 3 ed. Rio de Janeiro:

Guanabara, 2001.

VIEIRA, V. A. As tipologias, variações e características da pesquisa de marketing. Revista

FAE, Curitiba, v. 5, n. 1, p. 61-70, jan./abr. 2002.

\section{DADOS DOS AUTORES}

Nome: Leandro Carvalho Bassotto

E-mail: bassotto.lc@gmail.com

Curriculum Lattes: http://lattes.cnpq.br/1466573062055503

Doutorado em Administração pela Universidade Federal de Lavras; mestrado em Sistemas de Produção Agropecuária pela Universidade José do Rosário Vellano; especialista em Pecuária Leiteira com Ênfase em Manejo Intensivo de Pastagens pela Faculdade de Educação de Bom Despacho; graduação em Administração pela Universidade Anhanguera. Foi professor da Faculdade de Ciências e Tecnologias de Campos Gerais. Pesquisa temas relacionados a processos produtivos, gestão dos custos, análises de risco, financeiras e de viabilidade e gestão no agronegócio.

Nome: Luiz Kennedy Cruz Machado

E-mail: luizken@yahoo.com.br

Curriculum Lattes: http://lattes.cnpq.br/8252092863912566

Doutorado e mestrado em Administração pela Universidade Federal de Lavras; graduação em Administração pela Universidade Federal de São João Del Rei e em Ciências Contábeis pela Universidade de Franca. Foi professor adjunto na Faculdade de Ciências e Tecnologias de Campos Gerais e professor substituto da Universidade Federal de Alfenas, lotado no Instituto de Ciências Sociais Aplicadas. Tutor a distância do Curso Administração Pública promovido pelo CEAD-Universidade Federal de Lavras. 